\title{
Avaliação do efeito de critérios de projeto no dimensionamento de redes de macrodrenagem através da simulação hidrológico-hidráulica
}

\section{Effect of design criteria on the design of stormwater drainage systems based on hydrologic-hydraulic modeling}

Manuel José Mahunguana ${ }^{1}$ e Juan Martín Bravo ${ }^{2}$

${ }^{1}$ Estudante do Programa de Pós-graduação em Recursos Hídricos e Saneamento Ambiental Instituto de Pesquisas Hidráulicas-Universidade Federal do Rio Grande do Sul - Porto Alegre - RS - Brasil

${ }^{2}$ Professor adjunto do Departamento de Obras Hidráulicas e do programa de pós-graduação em Recursos Hídricos e Saneamento Ambiental no Instituto de Pesquisas Hidráulicas-Universidade Federal do Rio Grande do Sul- Porto Alegre - RS - Brasil

\section{RESUMO}

Os custos econômicos e perdas potenciais de vidas humanas resultantes de falhas em sistemas de drenagem de águas pluviais podem ser enormes, aumentando a importância da procura de melhores métodos de dimensionamento destes, sendo a estimativa do hidrograma de projeto parte essencial do dimensionamento. O método de precipitação de projeto é um dos mais usados para a estimativa do bidrograma de projeto com base nos dados de precipitação em bacias urbanas, entretanto, este método tem suas limitaçoes e incertezas que podem influenciar as características do hidrograma de projeto resultante, incertezas que são, em consequência, transferidas ao dimensionamento hidráulico das obras propostas. No presente trabalho são avaliados os efeitos da discretização espacial da bacia, da discretização temporal e posição do pico do bietograma de projeto, nas principais características do bidrograma de projeto resultante, utilizando a modelagem hidrológica-hidrodinâmica através dos modelos IPHS1 e SWMM 5.0. O impacto do valor adotado nesses critérios de projeto é ainda avaliado no dimensionamento bidráulico do sistema de macrodrenagem dos bairros suburbanos de Mavalane "A" e Maxaquene "A", localizados na cidade de Maputo em Moçambique. Os resultados obtidos mostram uma influência importante nas características do bidrograma de projeto: vazãa de pico, tempo de pico e volume parcial e, consequentemente, no dimensionamento da rede de macrodrenagem, sendo o efeito da discretização espacial da bacia o mais influente, seguido dos efeitos da posição do pico da chuva e intervalo de tempo.

Palavras Chave: Hidrograma de projeto. Hietograma de projeto. Discretização espacial. Discretização temporal. Posição do pico da chuva

\begin{abstract}
The economic costs and potential losses of human lives due to failure in stormwater drainage systems can be significant, calling for an improvement in methods used for its design, the estimation of the design flood hydrograph being an essential part of this process. The use of the design storm approach, also known as "single-event design-storm" is widespread in formulating design flood bydrograph from historical rainfall data in urban watersheds. However, this approach has uncertainties which can affect the resulting design flood hydrograph, and consequently, the bydraulic design of proposed structures. This study assessed the effects of spatial discretization of the watershed, the temporal discretization and peak position of the design byetograph, on the main features of the resulting design flood hydrograph. The impact of the adopted values on these design criteria is then assessed in the hydraulic design of the major stormwater drainage system of Mavalane "A" and Maxaquene "A" neighborboods, located in Maputo city in Mozambique. The results show an important influence of the assessed effects on the design flood hydrograph features :the bydrograph peak, time to peak and volume and, consequently, on the design of the major stormwater drainage system, the spatial discretization of the watershed being the most relevant, followed by the position of the byetograph peak and time interval.
\end{abstract}

Keywords: Design flood hydrograph. Design hyetograph. Spatial discretization. Temporal discretization. Hyetograph peak position 


\section{INTRODUÇÃO}

Os custos econômicos e as perdas potenciais de vidas humanas resultantes de falhas em sistemas de drenagem podem ser enormes, aumentando a importância da procura de melhores métodos de dimensionamento destes, sendo a estimativa do hidrograma de projeto parte essencial do dimensionamento. As melhores estimativas do hidrograma de projeto estão limitadas na disponibilidade de dados confiáveis (SMITHERS et al., 1997), porém, na maioria das vezes, não existem dados de vazão nos locais de interesse, principalmente em bacias de pequena escala (QUADER; GUO, 2006; SMITHERS et al., 1997). Contudo, existe maior disponibilidade nos dados de precipitação. Neste caso, é necessário estimar o hidrograma de projeto com base nos dados de precipitação, sendo o método de precipitação de projeto um dos mais usados. Neste método, o hietograma de projeto é calculado usando uma duração específica, em conjunto com uma curva Intensidade-Duração-Frequência (IDF) de um período de retorno que se assume conhecido (ADAMS; HOWARD, 1986). Este método tem seus problemas e limitações visto que o hietograma, assim como o hidrograma de eventos naturais, têm várias características tais como volume total, intensidade média, duração total, máxima intensidade total para uma duração específica, pico instantâneo, assimetria, etc., e não podem ser caracterizados apenas por um único período de retorno (ADAMS; HOWARD, 1986).

Uma das características típicas do hietograma de projeto é um pico fixo dentro da duração, porém, durante o dimensionamento a escolha da posição do pico do hietograma de projeto é ainda baseada em metodologias não muito claras, sendo muitas vezes posicionado a $50 \%$ da duração e algumas vezes no início, $25 \%, 75 \%$, final ou outras posições, em função da falta de maiores informações para sua caracterização. O principal problema é que, a posição do pico do hietograma de projeto influencia o valor de pico, tempo de pico, volume e distribuição temporal do hidrograma de projeto resultante, influência essa, que pode ser transferida ao dimensionamento hidráulico das obras propostas, podendo influenciar no seu custo, nas medidas de controle de cheias, planejamento e gestão de recursos hídricos (YUE et al., 2002). Allasia e Villanueva (2007a) verificaram que a colocação do pico do hietograma de projeto a $75 \%$ da duração aumenta em $20 \%$ a vazão de pico e em $8 \%$ o custo da macrodrenagem, e que a colocação deste a $25 \%$ da duração diminui em $24 \%$ a vazão de pico e em pouco mais de $15 \%$ o referido custo, quando comparados com os resultados obtidos usando hietograma com pico a $50 \%$ da duração (hietogramas de projeto gerados pelo método de blocos alternados). El-Jabiete e Sarraf (1991) também mostraram que em alguns casos de projetos de sistemas de águas pluviais, o uso de um valor constante no parâmetro da posição do pico da chuva (Método de Chicago) não é realístico e é necessário que este varie em função da duração do evento.

Outra questão que se levanta é o intervalo de tempo do hietograma de projeto, pois embora a literatura (e.g. TUCCI, 2005) recomende que este deve ser menor ou igual a um terço do tempo de pico $\left(\Delta t \leq \frac{1}{3} t_{p}\right)$ ou um quinto do tempo de concentração $\left(\Delta t \leq \frac{1}{5} t_{c}\right)$, a variação do intervalo de tempo dentro destes limites pode influenciar as características do hidrograma de projeto.
Mahunguana et al. (2013), em uma bacia hipotética observaram que o aumento do $\Delta$ t podia reduzir em até $25 \%$ a vazão de pico do hidrograma de projeto. Yu et al. (2012) também observaram que o aumento do intervalo de tempo subestimava a vazão de pico e o volume do hidrograma. Deste modo, surgem dúvidas sobre qual valor deve ser usado dentro dos referidos limites.

Outras questões importantes são: a representação espacial (concentrada ou em sub-bacias) e a variabilidade espacial das variáveis hidrológicas, das características de uso da terra e do tipo de solo (KHAKBAZ et al., 2009; BERNI et al., 2008).

Quanto à primeira questão, Wood et al. (1988) reportaram que, usando uma versão distribuída do Modelo TOPMODEL alimentado por diferentes eventos de precipitação, procuraram identificar a Área Elementar Representativa a partir da qual o efeito da discretização já não produz mais efeitos na vazão, tendo observado que a área era igual a $1 \mathrm{~km}^{2}$, numa bacia rural com área total de $17 \mathrm{~km}^{2}$. Para uma bacia predominantemente rural, mas com área total de $1.800 \mathrm{~km}^{2}$, Berniet al. (2008) usando o modelo HEC-HMS encontraram $300 \mathrm{~km}^{2}$ como área limite onde os eventos de precipitação e características do solo e uso de terra podiam ser consideradas de forma concentrada. O efeito da discretização espacial da bacia é mais pronunciado em bacias rurais (DANKENBRING; MAYS, 2009) e influencia também a estimativa do tempo de concentração (ALLASIA, 2002).

Quanto à segunda questão, no que tange à variabilidade espacial da precipitação, Wilson et al. (1979), usando um modelo hidrológico semi-distribuído mostraram que esta influencia o volume, o tempo de pico e o pico do hidrograma gerados por diferentes eventos de precipitação em uma bacia rural. Um resultado similar foi obtido por Yu et al. (2012), onde foi ainda ressaltada a influência da representação do relevo nas características do hidrograma. A importância da variabilidade espacial da precipitação foi também verificada por Berni et al. (2008) ao comparar hidrogramas obtidos considerando a precipitação uniformemente distribuída na bacia ou considerando sua variação em cada sub-bacia, tendo observado que a representação concentrada resultava em vazões menores no exutório da bacia.

Modelos de representação concentrada da bacia continuam sendo largamente usados, pois são mais simples e fornecem bons resultados quando devidamente calibrados. Kling e Gupta (2009) concluíram que os resultados fornecidos por modelos concentrados, mesmo quando calibrados, contêm certo grau de ruídos devido às deficiências na discretização espacial. A discretização da bacia providencia uma representação mais realística da heterogeneidade espacial dos processos hidrológicos, porém, os modelos distribuídos apresentam um elevado número de parâmetros, o que torna mais complexa a sua utilização e calibração e nem sempre a complexidade de um modelo é garantia de bons resultados.

Deste modo, a escolha da representação espacial da bacia vai influenciar o hidrograma de projeto resultante, e consequentemente, o dimensionamento das obras. Esta representação espacial é entendida neste estudo como a quantidade de sub-bacias a considerar.

Os três elementos: a posição do pico e o intervalo de tempo do hietograma de projeto e a discretização espacial da bacia, acabam sendo critérios de projeto definidos subjetiva- 
mente pelos projetistas em função da sua experiência prévia em situações de escassez de dados, situação comumente existente na maioria dos países em desenvolvimento.

Neste contexto, a motivação deste trabalho é investigar o impacto da variação destes critérios no dimensionamento hidráulico de sistemas de macrodrenagem de águas pluviais. São explorados de forma quantitativa os efeitos da discretização espacial da bacia, da posição do pico e discretização temporal do hietograma de projeto, nas principais características do hidrograma de projeto resultante. O estudo de caso focou-se no dimensionamento hidráulico do sistema de macrodrenagem de águas pluviais dos bairros de Mavalane "A" e Maxaquene "A", em Maputo, Moçambique.

É importante ressaltar que existem outros elementos que influenciam o dimensionamento hidráulico de sistemas de águas pluviais e que estão associados a incertezas na definição dos parâmetros dos diferentes métodos utilizados, como por exemplo, apresentado em Silveira (2010), Allasia e Villanueva (2007a), Allasia e Villanueva (2007b) e Allasia (2002).

\section{MATERIAIS E MÉTODOS}

\section{Área de estudo}

A área investigada corresponde a uma bacia urbana com área total de aproximadamente $2,91 \mathrm{~km}^{2}$, localizada na

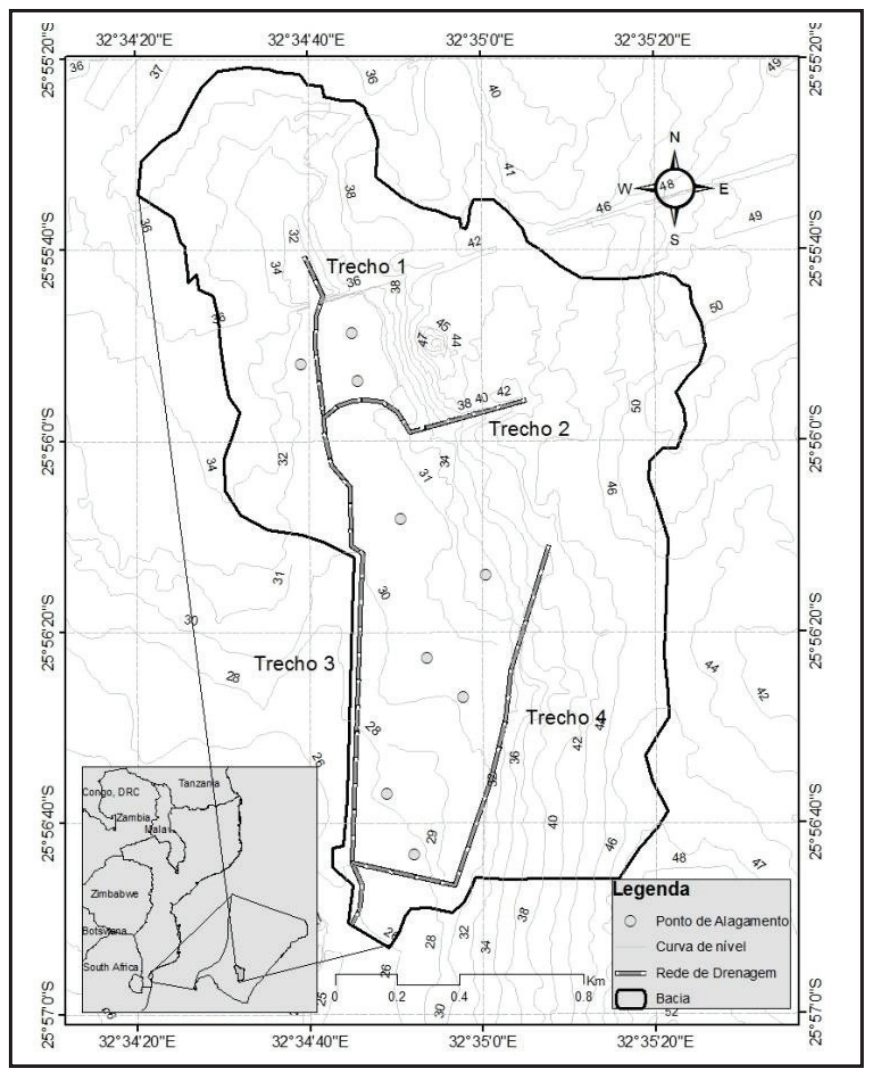

Figura 1 - Mapa da bacia, incluindo o sistema de drenagem, curvas de nível e pontos de alagamento dos bairros de Mavalane "A" e Maxaquene "A"

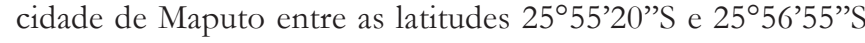
e longitudes $32^{\circ} 34^{\prime} 20^{\prime \prime} \mathrm{E}$ e $32^{\circ} 35^{\prime} 25^{\prime}$ 'E, conforme apresentado na Figura 1. A rede de drenagem da bacia é formada por um antigo sistema de drenagem de águas pluviais dos bairros suburbanos de Mavalane " $\mathrm{A}$ " e Maxaquene " $\mathrm{A}$ ", que inicia na Avenida Acordos de Lusaka (Trecho 1), nas imediações do Aeroporto Internacional de Maputo, ligando-se próximo à Praça dos Heróis Moçambicanos, a um pequeno trecho (Trecho 2) que segue o traçado da avenida das Forças Populares de Libertação de Moçambique (FPLM), continuando no sentido Norte-Sul (Trecho 3) ao longo da avenida Acordos de Lusaka, ligando-se a um outro trecho da Avenida Milagre Mabote (Trecho 4) a cerca de $200 \mathrm{~m}$ do seu exutório, onde descarrega em um outro sistema maior localizado na faixa central da Avenida Joaquim Chissano. O canal principal (Trecho 1 e Trecho 3) é trapezoidal aberto, com aproximadamente $2.218 \mathrm{~m}$ de comprimento e $0,37 \%$ de declividade média. O canal das FPLM (Trecho 2) com cerca de $740 \mathrm{~m}$ de comprimento e 1,16\% de declividade média, inicia nas imediações do Hospital Geral de Mavalane, com forma retangular fechada, descendo a Avenida das FPLM até próximo a Praça dos Heróis Moçambicanos, onde passa a apresentar uma seção transversal trapezoidal aberta, a qual faz um traçado semi-circular e descarrega no canal principal da avenida Acordos de Lusaka. O canal da Avenida Milagre Mabote (Trecho 4), com aproximadamente $1.500 \mathrm{~m}$ de comprimento e $1,01 \%$ de declividade média, inicia nas imediações do Estádio $1^{\circ}$ de Maio, no bairro de Maxaquene, com forma trapezoidal, descendo esta avenida na direção Nordeste-Sudoeste até a Escola Primária Unidade 24, onde passa a apresentar uma seção retangular aberta, e o traçado segue para Noroeste até descarregar no canal principal da avenida Acordos de Lusaka.

O clima na bacia é Tropical Úmido, com estação quente e úmida entre Outubro e Março, e estação seca e fresca entre Abril e Setembro. O clima é afetado pela posição da Zona de Convergência Intertropical do Sul, anticiclones do Atlântico Sul e do Oceano Índico, e depressões térmicas durante a estação quente (DNA, 2005). Entre o período de 1979 e 2012, a temperatura e precipitação médias anuais na bacia foram $23^{\circ} \mathrm{C}$ e $813 \mathrm{~mm}$, respetivamente.

\section{Discretização espacial e determinação dos parâ- metros da bacia}

Em função das características da bacia hidrográfica, quatro diferentes discretizações espaciais foram analisadas, considerando 1, 5, 7 e 12 sub-bacias, e suas características físicas apresentadas na Tabela 1. Foram usadas curvas de nível da cidade de Maputo com escala de 1:5000, imagens do Google Earth e ArcGIS 9.3.1 para determiná-las. Foram testadas seis equações de tempo de concentração para bacias urbanas, retiradas do estudo de Silveira (2005). Das seis equações, foi escolhida a equação de McCuen: $\mathrm{Tc}=2,25 \mathrm{i}^{-0,7164} \mathrm{~L}^{0,5552} \mathrm{~S}^{-0,2070}$, onde Tc é tempo de concentração (h), L é comprimento do percurso hidráulico $(\mathrm{km}), S$ é declividade média $(\mathrm{m} / \mathrm{m})$ e $i$ é intensidade da chuva, considerada igual a $35 \mathrm{~mm} / \mathrm{h}$ conforme recomendado por McCuen et al. (1984). Esta equação foi escolhida por apresentar limites de validade mais próximos aos da área de estudo. 
Mahunguana e Bravo: Avaliação do efeito de critérios de projeto no dimensionamento de redes de macrodrenagem através da simulação hidrológico-hidráulica

Tabela 1 - Parâmetros das sub-bacias

\begin{tabular}{|c|c|c|c|c|c|}
\hline $\begin{array}{l}\text { Sub- } \\
\text { bacia }\end{array}$ & A & $\mathbf{L}$ & $\mathbf{S}$ & Tc & $\mathrm{CN}$ \\
\hline \multicolumn{6}{|c|}{ Discretização em 1 sub-bacia } \\
\hline S1 & 2,91 & 2,99 & 0,0037 & 62 & 91,8 \\
\hline \multicolumn{6}{|c|}{ Discretização em 5 sub-bacias } \\
\hline S1 & 0,87 & 1,85 & 0,0038 & 47 & 93,1 \\
\hline $\mathrm{S} 2$ & 0,82 & 1,52 & 0,0131 & 33 & 88,9 \\
\hline S3 & 0,52 & 0,56 & 0,0107 & 20 & 94,0 \\
\hline S4 & 0,64 & 0,71 & 0,0170 & 20 & 91,7 \\
\hline S5 & 0,06 & 0,34 & 0,0058 & 17 & 94,0 \\
\hline \multicolumn{6}{|c|}{ Discretização em 7 sub-bacias } \\
\hline S1 & 0,72 & 1,36 & 0,0037 & 40 & 92,9 \\
\hline $\mathrm{S} 2$ & 0,65 & 1,52 & 0,0125 & 33 & 87,8 \\
\hline S3 & 0,15 & 0,44 & 0,0045 & 21 & 94,0 \\
\hline S4 & 0,17 & 0,74 & 0,0189 & 20 & 93,0 \\
\hline S5 & 0,52 & 0,56 & 0,0107 & 20 & 94,0 \\
\hline S6 & 0,64 & 0,71 & 0,0170 & 20 & 91,7 \\
\hline $\mathrm{S} 7$ & 0,06 & 0,34 & 0,0058 & 17 & 94,0 \\
\hline \multicolumn{6}{|c|}{ Discretização em 12 sub-bacias } \\
\hline S1 & 0,37 & 0,82 & 0,0061 & 27 & 94,0 \\
\hline $\mathrm{S} 2$ & 0,14 & 0,45 & 0,0089 & 18 & 93,0 \\
\hline S3 & 0,21 & 0,72 & 0,0138 & 21 & 91,0 \\
\hline S4 & 0,15 & 0,44 & 0,0045 & 21 & 94,0 \\
\hline S5 & 0,28 & 0,90 & 0,0145 & 24 & 84,0 \\
\hline S6 & 0,25 & 0,76 & 0,0105 & 23 & 92,0 \\
\hline $\mathrm{S} 7$ & 0,12 & 0,80 & 0,0025 & 32 & 88,0 \\
\hline S8 & 0,17 & 0,74 & 0,0149 & 21 & 93,0 \\
\hline S9 & 0,09 & 0,52 & 0,0116 & 18 & 90,0 \\
\hline S10 & 0,52 & 0,56 & 0,0107 & 20 & 94,0 \\
\hline S11 & 0,55 & 0,71 & 0,0170 & 20 & 92,0 \\
\hline $\mathrm{S} 12$ & 0,06 & 0,34 & 0,0058 & 17 & 94,0 \\
\hline
\end{tabular}

A: área $\left(\mathrm{km}^{2}\right)$, L: comprimento do percurso hidráulico $(\mathrm{m}), \mathrm{S}$ : declividade $(\mathrm{m} / \mathrm{m})$, I: intensidade da chuva $(\mathrm{mm} / \mathrm{h})$, Tc: tempo de concentração ( $\mathrm{min}), \mathrm{CN}$ : parâmetro $\mathrm{CN}$
Em função da escassez de dados, as curvas de nível foram também usadas para determinar as cotas superficiais nos canais que, subtraídas pelas profundidades medidas em campo, definiram as cotas do fundo do canal em cada nó. Assim foi possível representar a situação atual da bacia no SWMM 5.0, conforme ilustra a Figura 2.

\section{Cálculo de hidrogramas de projeto por sub-bacia}

A equação das curvas IDF da cidade de Maputo na forma $i(\mathrm{~mm} / \mathrm{h})=a \times t(\mathrm{~min})^{b}$ e o método dos blocos alternados foram usados para calcular os hietogramas de projeto com durações de 90 minutos e $24 \mathrm{~h}$, e intervalos de tempo de 1,2 , 3, 4 e 5 minutos. O período de retorno considerado foi de 10 anos. Na equação da IDF $a, b$ são parâmetros adimensionais; té a duração da precipitação (min); $i$ é a intensidade da chuva $(\mathrm{mm} / \mathrm{h})$ e $t r$ é o período de retorno (anos). Para $t r=10$ anos, $a=797,3841$ e $b=-0,5869$ (BR, 2003).

As durações de 90 minutos e $24 \mathrm{hs}$ foram escolhidas por serem as mais usadas no dimensionamento de sistemas pluviais, cumprindo ainda com o pré-requisito do evento de precipitação apresentar uma duração maior ou igual ao tempo de concentração da bacia hidrográfica (62 minutos). Dessa forma, em cada uma das sub-bacias, para cada intervalo de tempo e duração, foram estimados hietogramas de projeto com o pico localizado no início, aos $25 \%, 50 \%, 75 \%$ e final da duração, totalizando 50 hietogramas ( 2 durações x 5 posições do pico x 5 intervalos de tempo). Os hietogramas foram utilizados como dados de entrada ao programa IPHS1 para obter os hidrogramas de projeto por sub-bacia (1.250 hidrogramas), os quais foram usados posteriormente como dados de entrada para a propagação hidrodinâmica na rede de canais no modelo SWMM 5.0. Para tal, os hidrogramas foram introduzidos nos 36 nós que unem os trechos de canais apresentados na Figura 2, de forma concentrada ou distribuída ao longo dos nós de incidência, conforme a discretização espacial. Os métodos de

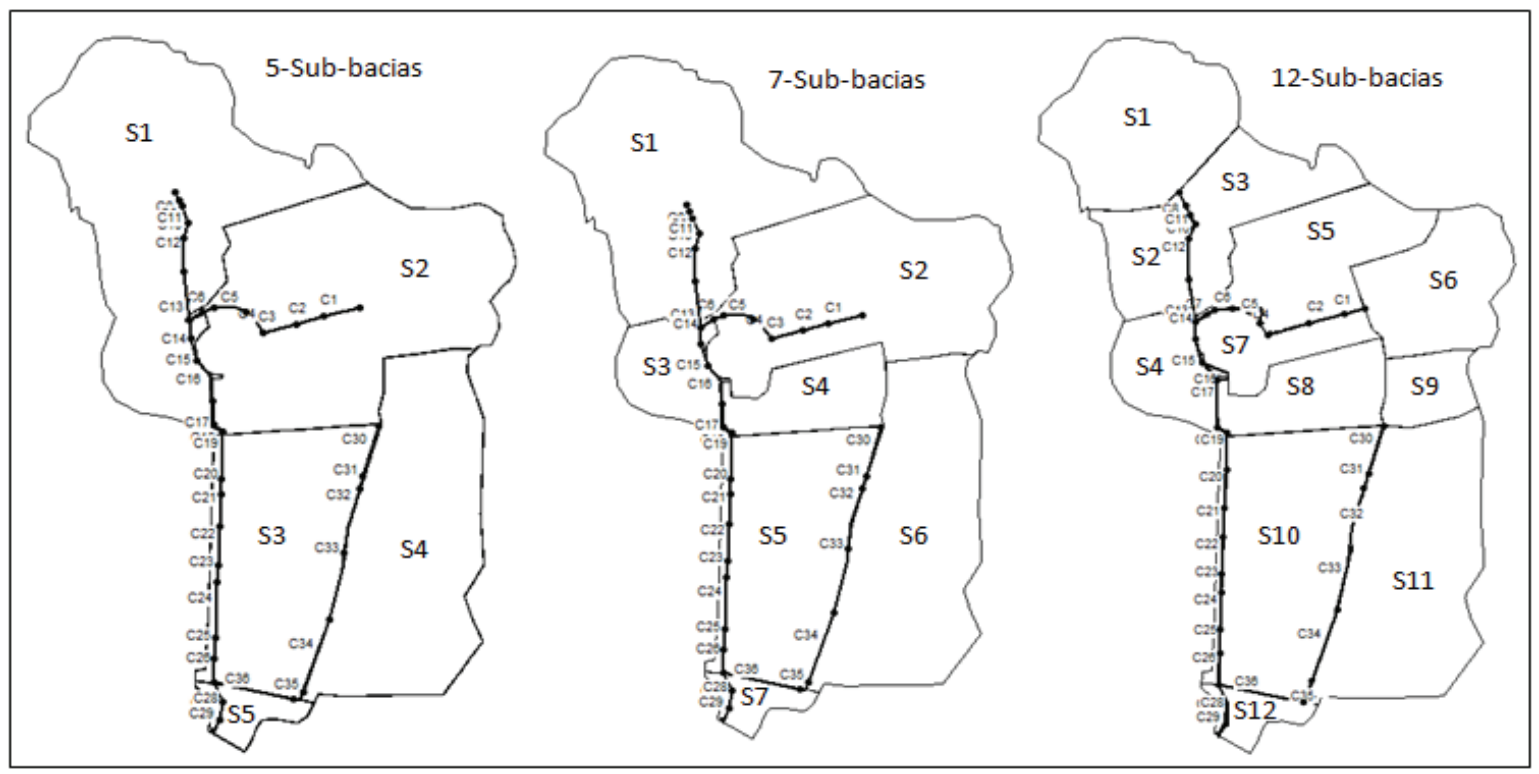

Figura 2 - Representação da bacia no SWMM 5.0 
separação de escoamento e propagação do escoamento superficial adotados no IPHS1 foram o método da curva número do SCS e o método do hidrograma unitário sintético triangular, também do SCS, respetivamente.

\section{Variáveis analisadas}

Três variáveis do hidrograma de projeto: tempo de pico, volume parcial e vazão de pico e, uma variável do dimensionamento: área da seção transversal do canal, foram analisadas no exutório da bacia. Para a vazão de pico, volume parcial do hidrograma de projeto e a área da seção transversal do canal foram analisados os efeitos da discretização espacial da bacia, do intervalo de tempo e da posição do pico da chuva. Para o tempo de pico do hidrograma de projeto foi analisado apenas o efeito da discretização espacial da bacia.

O volume parcial representa o volume do hidrograma de projeto acima de um determinado valor de vazão de corte, considerado neste estudo como $50 \mathrm{~m}^{3} / \mathrm{s}$. O uso desta variável tentou refletir as mudanças na distribuição temporal da região de maiores vazões do hidrograma de projeto, região que tipicamente mais influencia o dimensionamento de estruturas de amortecimento como, por exemplo, as bacias de detenção off-line. $\mathrm{O}$ valor considerado como vazão de corte representa, aproximadamente, a maior vazão obtida nas diferentes análises da bacia concentrada.

As análises do efeito da discretização espacial consistiram em determinar as alterações percentuais dos valores das variáveis nas discretizações de 5, 7 e 12 sub-bacias, em relação aos valores correspondentes da bacia concentrada (discretização em 1 sub-bacia). No intervalo de tempo, as análises consistiram em determinar as alterações percentuais dos valores das variáveis nos intervalos de 2, 3, 4 e 5 minutos, em relação aos valores correspondentes do intervalo de 1 minuto. Na posição do pico da chuva, as análises consistiram em determinar as alterações percentuais dos valores das variáveis das posições do pico no início, 25\%, 75\% e final, em relação aos valores correspondentes da posição do pico aos $50 \%$ da duração do hietograma de projeto.

\section{Propagação hidrodinâmica e dimensionamento hidráulico do sistema de drenagem no SWMM 5.0}

Os hidrogramas determinados no processo anterior foram introduzidos nos nós do sistema de drenagem e propagados no modelo SWMM 5.0. Os resultados aqui apresentados correspondem ao exutório da bacia hidrográfica, localizado no fim do Trecho 3, concretamente no canal C29. Assim, foram iniciadas as simulações considerando as diferentes discretizações espaciais (1, 5, 7 e 12 sub-bacias), intervalos de tempo (1, 2, 3, 4 e 5 minutos), durações ( $90 \mathrm{~min}$ e $24 \mathrm{~h}$ ) e posições do pico da chuva (início, 25\%, 50\%, 75\% e final). Em cada simulação foi feito o dimensionamento hidráulico de todo o sistema, e este consistiu em manipular as medidas geométricas das seções transversais (profundidade, largura, diâmetro e taludes) até que em cada trecho, o sistema conseguisse escoar a vazão até 95\% da sua capacidade, sem produzir alagamentos nem existindo instabilidades na modelagem, verificando ainda que o escoamento apresentasse velocidade inferior a $5 \mathrm{~m} / \mathrm{s}$ em todos os trechos.

\section{RESULTADOS E DISCUSSÃO}

\section{Efeito no tempo de pico do hidrograma de projeto}

A Figura 3 apresenta a alteração percentual do tempo de pico com a discretização espacial da bacia para eventos de precipitação com durações de 90 minutos e 24 horas. Observa-se que para todas as posições do pico do hietograma de projeto, o tempo de pico tende a diminuir com o aumento do número de sub-bacias, e este efeito é mais intenso para a duração de 90 minutos.

Os resultados aqui obtidos mostram que o efeito da discretização da bacia em sub-bacias afeta o tempo de pico, na medida em que o tempo de pico pode diminuir em até mais da metade, o que poderá influenciar o dimensionamento de unidades de armazenamento como bacias de detenção. Embora a posição do pico de $50 \%$ seja a mais preferida nos projetos, os resultados ilustram que nesta posição, a discretização espacial pode reduzir, aproximadamente, em $24 \%$ e $2 \%$ o tempo de pico do hidrograma de projeto resultante, quando as durações de 90 minutos e 24 horas são adotadas.
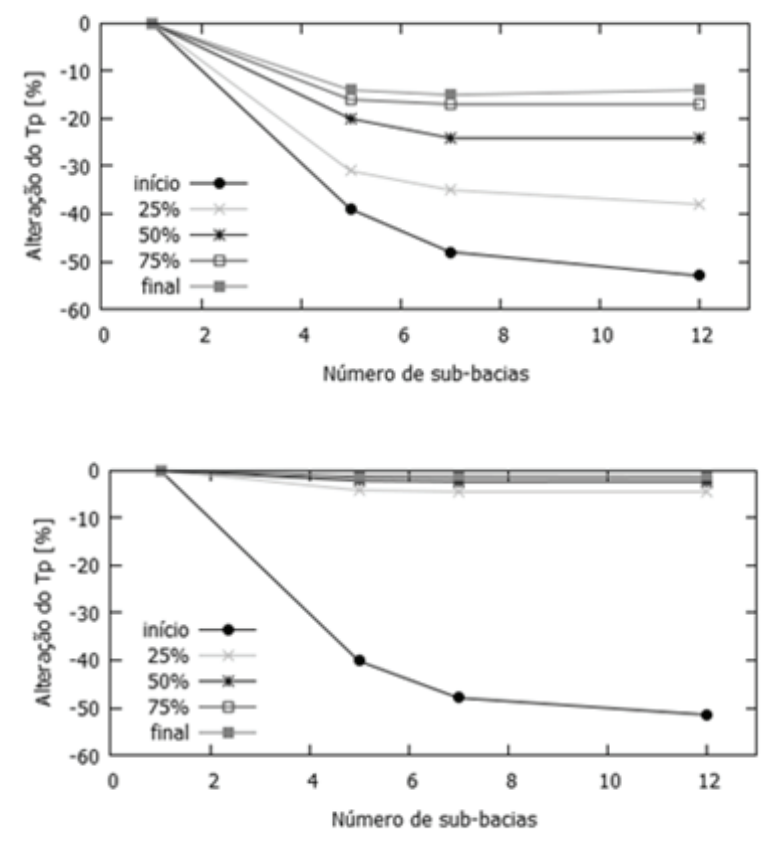

Figura 3 - Efeito da discretização espacial da bacia no tempo de pico (Tp) do hidrograma de projeto, durações $90 \mathrm{~min}$ e $24 \mathrm{hs}$

\section{Efeitos no volume parcial do hidrograma de projeto}

A Figura 4 apresenta o volume parcial (valor médio considerando os diferentes intervalos de tempo) para diferentes discretizações espaciais da bacia e posições do pico da chuva, considerando as duas durações.

O volume parcial para a posição do pico no início é nulo 


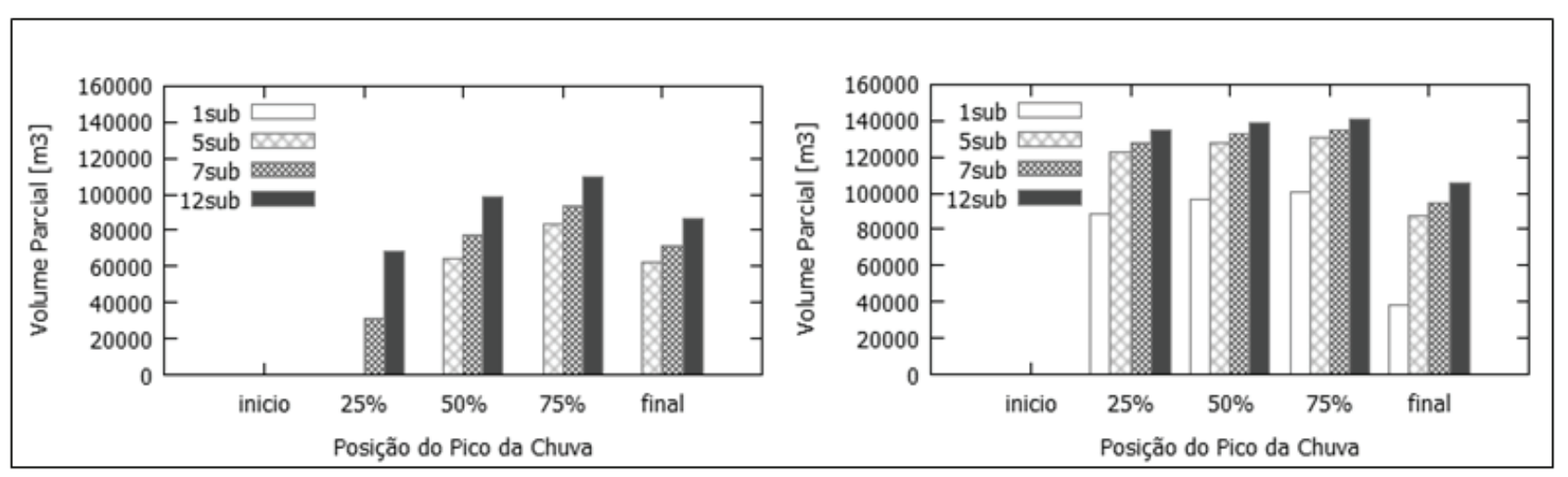

Figura 4 - Efeitos da discretização espacial da bacia e posição do pico da chuva no volume parcial do hidrograma de projeto, no exutório da bacia, durações $90 \mathrm{~min}$ e $24 \mathrm{hs}$

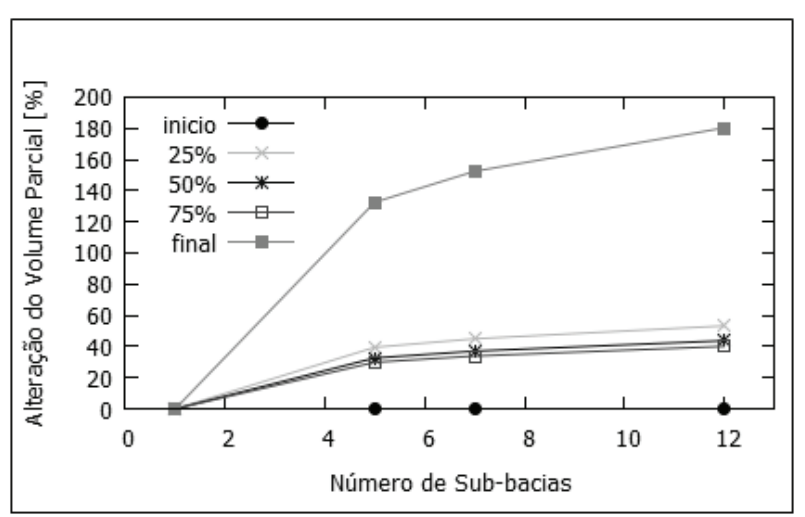

Figura 5 - Efeito da discretização espacial da bacia no volume parcial do hidrograma de projeto, duração $24 \mathrm{hs}$

$\left(0 \mathrm{~m}^{3}\right)$ em todos os casos. O volume parcial é também nulo para o evento de 90 minutos quando analisada a bacia concentrada, independentemente da posição do pico de chuva. Isso significa que no caso de um projeto hipotético que verifique se seria necessária a construção de uma bacia de detenção offline numa bacia onde existe um canal capaz de propagar uma vazão de pico de $50 \mathrm{~m}^{3} / \mathrm{s}$, a resposta seria negativa se a bacia for simulada de forma concentrada (considerando os mesmos resultados apresentados na Figura 4, com evento de precipitação com duração de 90 minutos). Entretanto, a resposta seria positiva se as análises forem feitas usando pelo menos a discretização em 7 sub-bacias e posição do pico da chuva de $25 \%$, resultando em um volume excedente de $30.000 \mathrm{~m}^{3}$, aproximadamente. Esse valor ainda pode crescer até os $110.000 \mathrm{~m}^{3}$, aproximadamente, considerando a discretização em 12 sub-bacias e a posição do pico da chuva em $75 \%$ da duração.

Para a duração de 24 horas, considerando a bacia concentrada e o pico do evento de precipitação aos $75 \%$ da duração, existiria um volume excedente igual a $100.000 \mathrm{~m}^{3}$, aproximadamente. Porém, esse valor volta a crescer com o aumento da discretização espacial da bacia, sendo que para o mesmo evento de precipitação, o volume excedente resulta igual a $140.000 \mathrm{~m}^{3}$, aproximadamente.

A Figura 5 apresenta alteração percentual do volume parcial do hidrograma de projeto com a discretização espacial da bacia para duração de 24 horas. Observa-se que volume parcial tende a aumentar com o aumento do número de sub-bacias, e este aumento varia com a posição do pico do evento de precipitação, sendo a posição do final a que apresenta o maior aumento com $180 \%$, e a do início a que apresenta o menor aumento com $0 \%$.

O aumento do volume com o aumento do número de sub-bacias foi também observado por Wood et al. (1988) e Yu et al. (2012), embora eles tenham analisado o volume total e usado como base o tamanho da célula regular de modelos distribuídos. Ghosh e Hellweger (2012) verificaram que este efeito causava variações menores do que $2 \%$ no volume total. Deve-se ressaltar que neste trabalho é analisado o volume acumulado acima de certos valores da vazão do hidrograma de projeto, e que são de maior interesse na área de drenagem urbana, e não

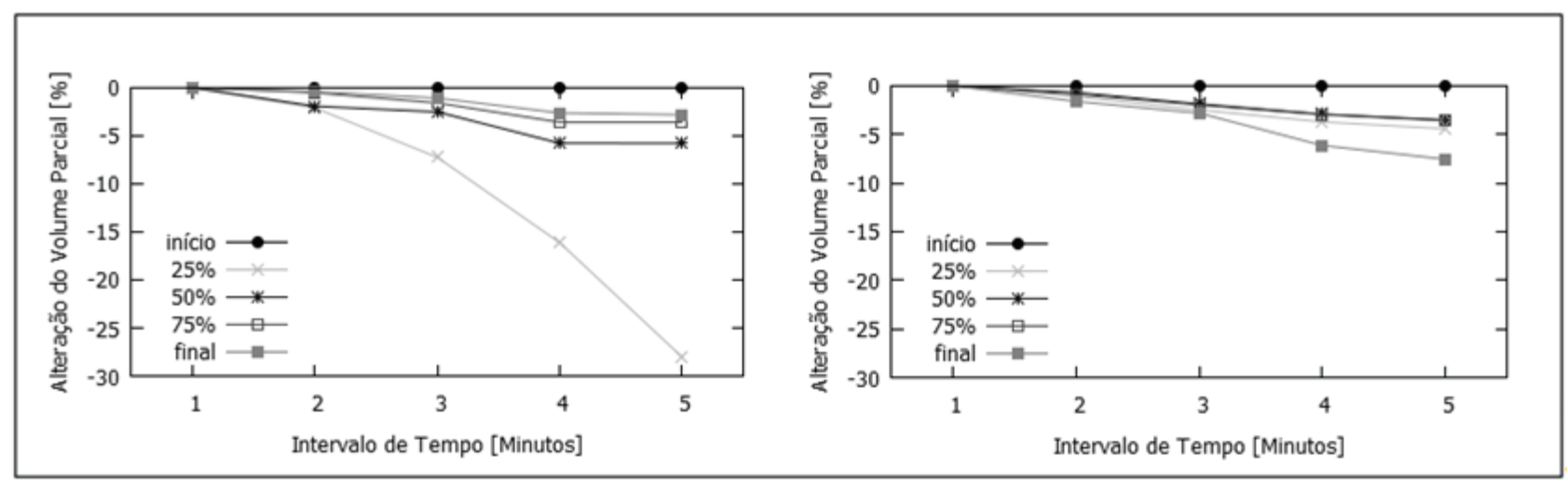

Figura 6 - Efeito do intervalo de tempo da chuva no volume parcial do hidrograma de projeto, durações $90 \mathrm{~min}$ e $24 \mathrm{hs}$ 


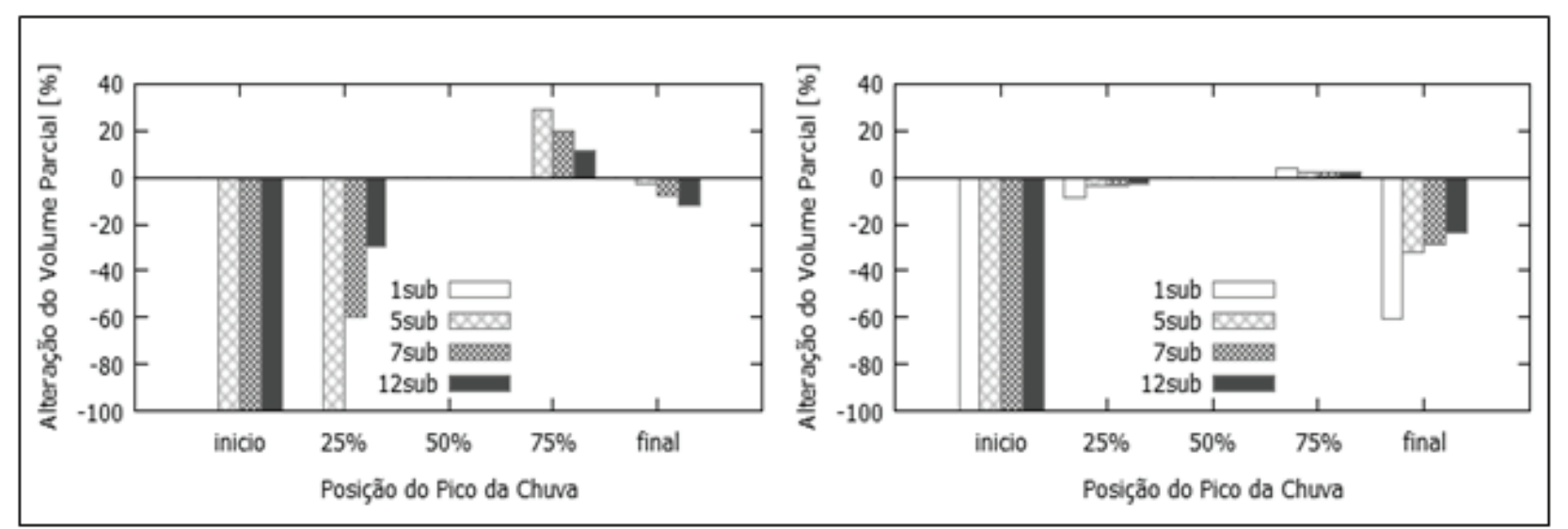

Figura 7 - Efeito da posição do pico da chuva no volume parcial do hidrograma de projeto, durações $90 \mathrm{~min}$ e $24 \mathrm{hs}$

o volume total do hidrograma como feito pelos autores citados. Em eventos de projeto como aqui calculados, o volume total do hidrograma de projeto não é alterado com a discretização espacial da bacia, pois o CN médio da bacia concentrada e discretizada continua o mesmo.

Na Figura 6 é apresentado o efeito do intervalo de tempo da chuva no volume parcial do hidrograma de projeto, e através desta pode se observar que o volume parcial tende a diminuir com o aumento do intervalo de tempo, sendo o efeito mais intenso durante o evento com duração de 90 minutos, no qual atinge uma diminuição de $28 \%$ na posição do pico aos $25 \%$ da duração da chuva.

O volume parcial do hidrograma de projeto é também influenciado pela posição do pico da chuva conforme ilustrado na Figura 7, e o seu padrão é caracterizado pela diminuição nas posições de pico no início, $25 \%$ e final e aumento na posição do pico a $75 \%$, independentemente da discretização espacial e duração considerada.

Os resultados obtidos ilustram que o volume parcial é influenciado tanto pela discretização espacial da bacia, pelo intervalo de tempo bem como pela posição do pico do hietograma de projeto, sendo a discretização espacial o que mais afeta o volume parcial.

\section{Efeitos na vazão de pico do hidrograma de projeto}

A Figura 8 apresenta a alteração percentual da vazão de pico no exutório da bacia com o aumento da discretização espacial da bacia para eventos com duração de 90 minutos e 24 horas. Observa-se nesta figura que a vazão de pico tende a aumentar na medida em que o número de sub-bacias aumenta. Além disso, o aumento da vazão de pico é maior quando o pico da chuva é posicionado entre $25 \%$ e final do hietograma e menor quando este é posicionado no início. Isso é mais evidente quando o evento de precipitação possui uma duração de 24 horas, visto que considerando uma duração de 90 minutos a vazão de pico obtida com o hietograma com pico na posição do final, discretização em 12 sub-bacias, apresentou-se ligeiramente abaixo dos valores obtidos com o pico do hietograma nas posições de $25 \%$ e $50 \%$.

O aumento da vazão de pico considerando hietogramas com pico nas posições de $25 \%, 50 \%$ e $75 \%$ apresenta valores muito próximos entre si, e isso é mais evidente na duração de 24 horas. Na duração de 90 minutos, um aumento máximo de $72 \%$ na vazão de pico foi provocado pelo aumento da discretização espacial da bacia (pico do hietograma na posição de $25 \%$ da duração), enquanto que, na duração de 24 horas o máximo aumento foi de $64 \%$.

Com base nos resultados apresentados na Figura 8 pode-se concluir que quando a bacia é discretizada em sub-bacias existe um aumento das vazões de pico e que, para o estudo de caso analisado, tende a ser maior para menores durações do hietograma de projeto. Este comportamento já tinha sido observado por Mahunguana et al. (2013) em uma bacia hipotética

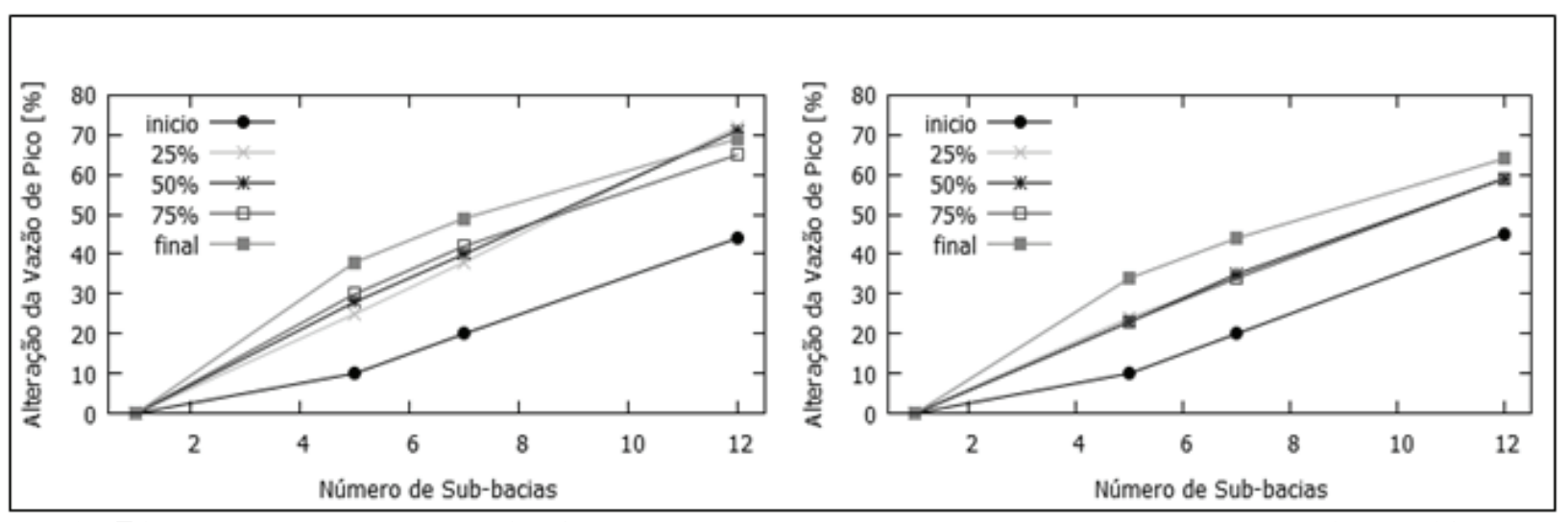

Figura 8 - Efeito da discretização espacial da bacia na vazão de pico do hidrograma de projeto, durações 90 min e $24 \mathrm{hs}$ 


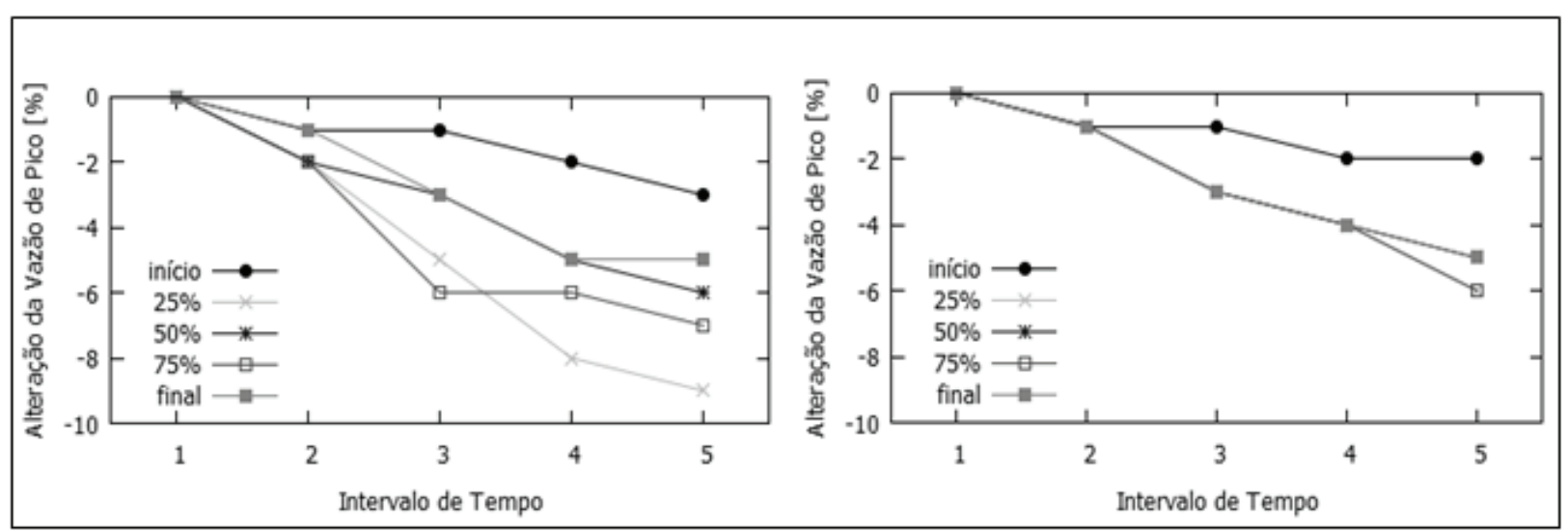

Figura 9 - Efeito do intervalo de tempo da chuva na vazão de pico do hidrograma de projeto, durações 90 min e $24 \mathrm{hs}$

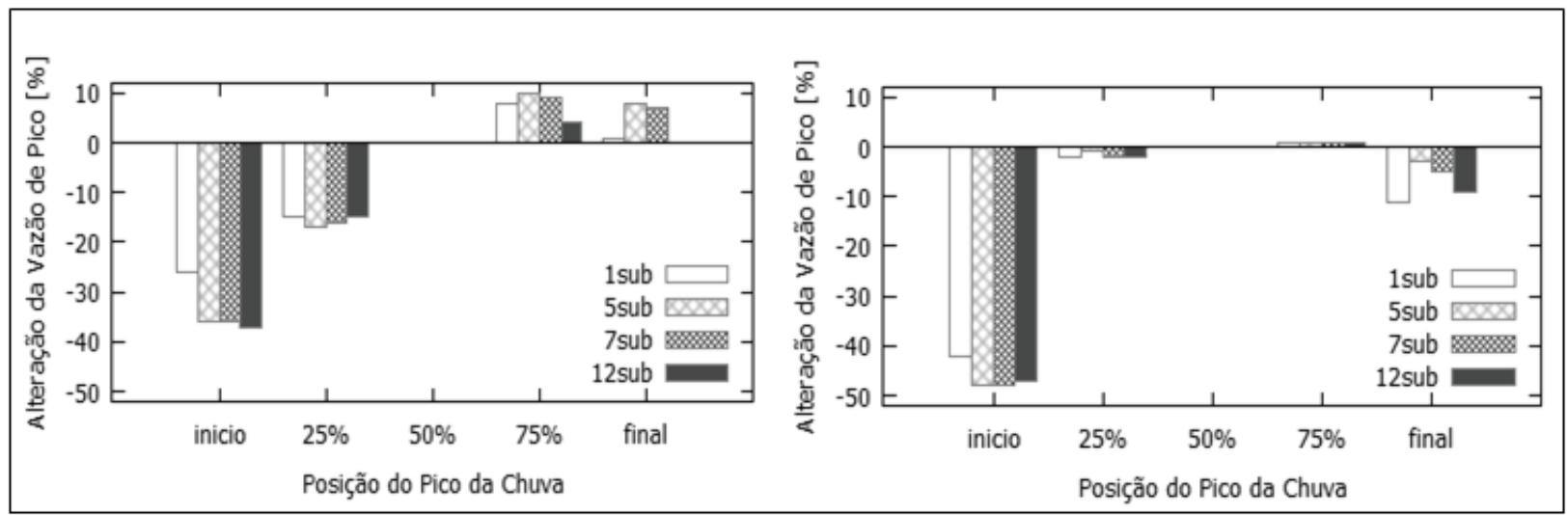

Figura 10 - Efeito da posição do pico da chuva na vazão de pico do hidrograma de projeto, durações 90 min e $24 \mathrm{hs}$

simplificada, com aumento máximo de $47 \%$ na vazão de pico. Ghosh e Hellweger (2012) observaram que o efeito da discretização espacial da bacia na vazão de pico também depende das características do hietograma de projeto, podendo aumentar a vazão de pico em eventos mais intensos, ou diminuir a vazão de pico em eventos menos intensos.

A Figura 9 apresenta a alteração percentual da vazão de pico quando o intervalo de tempo usado no cálculo do hietograma de projeto foi aumentado de 1 minuto para 2, 3, 4 e 5 minutos. Em todos os gráficos é possível observar que a vazão de pico diminui com o aumento do intervalo de tempo, e que este efeito é mais intenso na duração de 90 minutos, no qual a vazão chega a diminuir em até $9 \%$, aproximadamente. $\mathrm{Na}$ duração de 24 horas a diminuição máxima foi de $6 \%$, aproximadamente. A diminuição da vazão de pico com o aumento do intervalo de tempo de 1 para 2, 4, 6 e 10 minutos foi observada por Mahunguana et al. (2013) em uma bacia hipotética simplificada, com valor máximo de 25\%. Yuet al. (2012) também verificaram que o aumento do intervalo de tempo subestimava os picos dos hidrogramas observados, sem no entanto, referir quantitativamente os valores.

Por fim, a Figura 10 apresenta o efeito da posição do pico da chuva na vazão de pico dos hidrogramas resultantes no exutório da bacia. De forma geral observa-se nos resultados obtidos que, posicionar o pico da chuva no início do hietograma pode diminuir em até $48 \%$ o pico do hidrograma de projeto se comparado a aquele que seria obtido posicionando o pico da chuva aos 50\% da duração. Posicionando o pico da chuva aos $25 \%$ da duração, o pico do hidrograma poder ser diminuído em até $17 \%$. Posicionando o pico da chuva aos $75 \%$ da duração, o pico do mesmo hidrograma pode ser aumentado em até $10 \%$. Entretanto, posicionando o pico da chuva no final do hietograma, o pico do hidrograma pode ser aumentado em até $8 \%$ ou diminuído em até $10 \%$, dependendo da duração adotada.

$\mathrm{O}$ aumento e a diminuição da vazão de pico quando o pico da chuva é posicionado aos $75 \%$ e $25 \%$ da duração, foi também observado por Šraj et al. (2010), Allasia e Villanueva (2007a), Daniil et al. (2005) e Mahunguana et al. (2013), tendo encontrado aumentos de 3\%, 20\%, 21\% e 18\% na posição de $75 \%$ e diminuições de $5 \%, 24 \%$ e $27 \%$ e $24 \%$ na posição de $25 \%$, respetivamente. Daniil et al. (2005) observaram ainda uma diminuição desses valores com o aumento do período de retorno do evento.

\section{Efeitos na área da seção transversal do canal}

A Figura 11 apresenta a alteração percentual da área da seção transversal do canal C29 com o aumento da discretização espacial da bacia para eventos com duração de 90 minutos e 24 horas. Observa-se que a área da seção transversal do canal C29 aumenta com o aumento do número de sub-bacias, chegando a atingir cerca de $60 \%$ de aumento em ambas as durações do evento de precipitação. Os valores das alterações percentuais considerando hietogramas com pico nas posições de 25\%, 50\% 

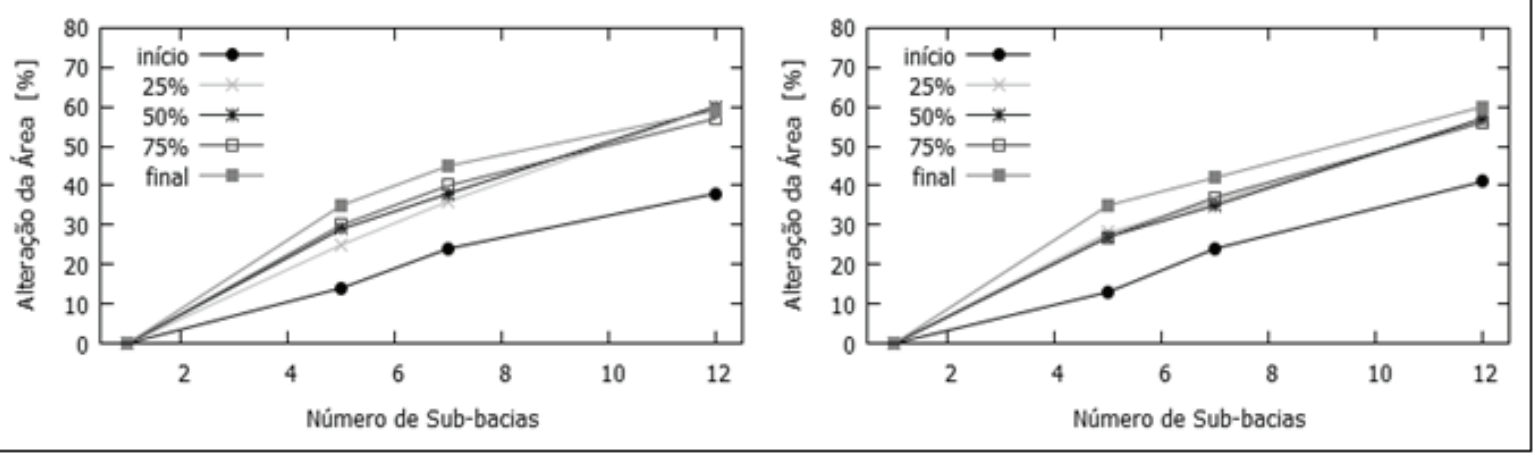

Figura 11 - Efeito da discretização espacial da bacia na área da seção transversal do canal, durações 90 min e $24 \mathrm{hs}$

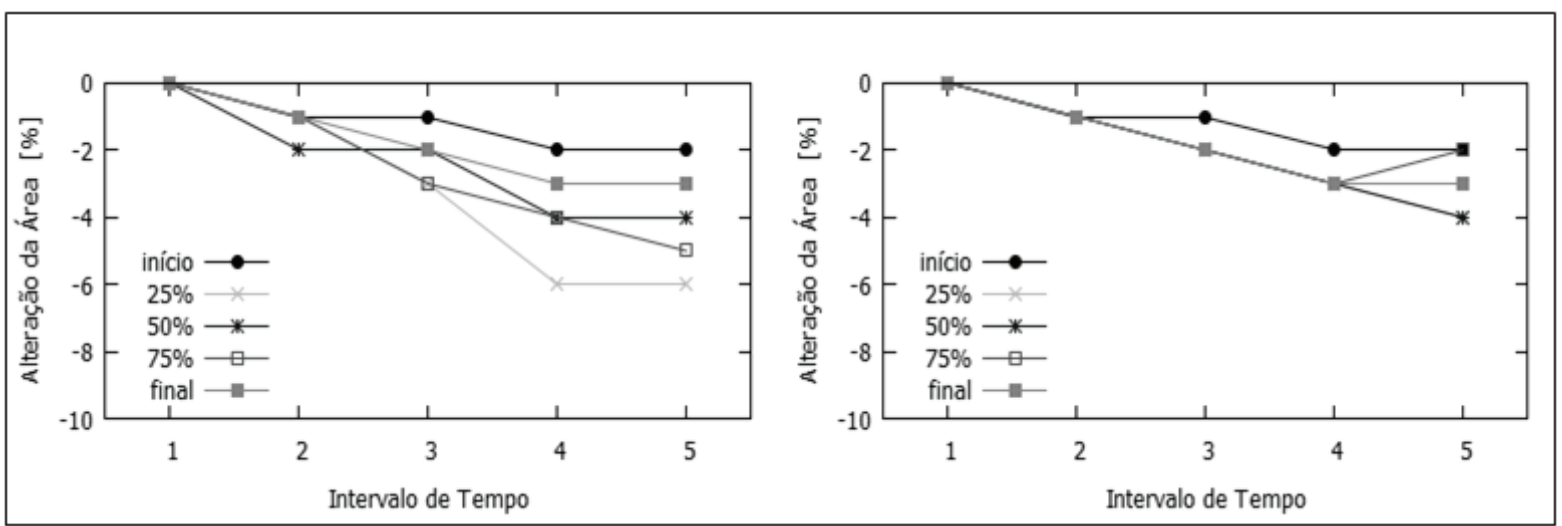

Figura 12 - Efeito do intervalo de tempo da chuva na área da seção transversal do canal, durações $90 \mathrm{~min}$ e $24 \mathrm{hs}$

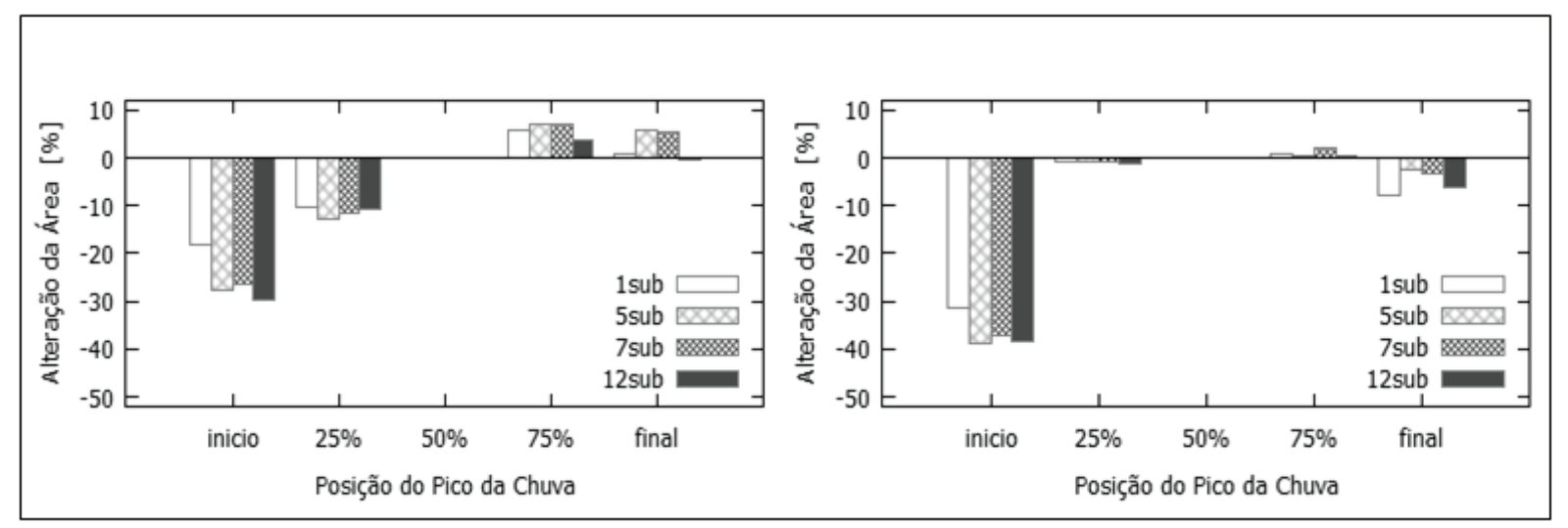

Figura 13 - Efeito da posição do pico da chuva na área da seção transversal do canal, durações 90min e 24hs

e 75\% não apresentam muitas diferenças entre si, e isso é mais evidente na duração de 24 horas. Esse comportamento está de acordo com o observado na análise do efeito da discretização espacial da bacia na vazão de pico.

A Figura 12 apresenta a alteração percentual da área da seção transversal do canal C29, quando o intervalo de tempo usado no cálculo do hietograma de projeto foi aumentado de 1 minuto para 2, 3, 4 e 5 minutos. Observa-se uma diminuição da área da seção transversal com o aumento do intervalo de tempo, com uma máxima diminuição de 4\% e 6\%, aproximadamente, para as durações de 24 horas e 90 minutos, respetivamente.

Por fim, a Figura 13 apresenta o efeito da posição do pico da chuva na área da seção transversal do canal C29. De forma geral, observa-se nos resultados obtidos que posicionar o pico da chuva no início do hietograma de projeto pode diminuir em até 39\% a área da seção transversal se comparada àquela que seria obtida posicionando o pico da chuva aos $50 \%$ da duração. Posicionando o pico da chuva aos $25 \%$ da duração, a área da seção transversal pode ser diminuída em até $13 \%$. Posicionando o pico da chuva aos $75 \%$ da duração, a área da seção transversal pode ser aumentada em até $7 \%$. Entretanto, posicionando o pico da chuva no final do hietograma, a área da seção transversal pode ser aumentada em até $6 \%$ ou diminuída em até $8 \%$, dependendo da duração adotada. 


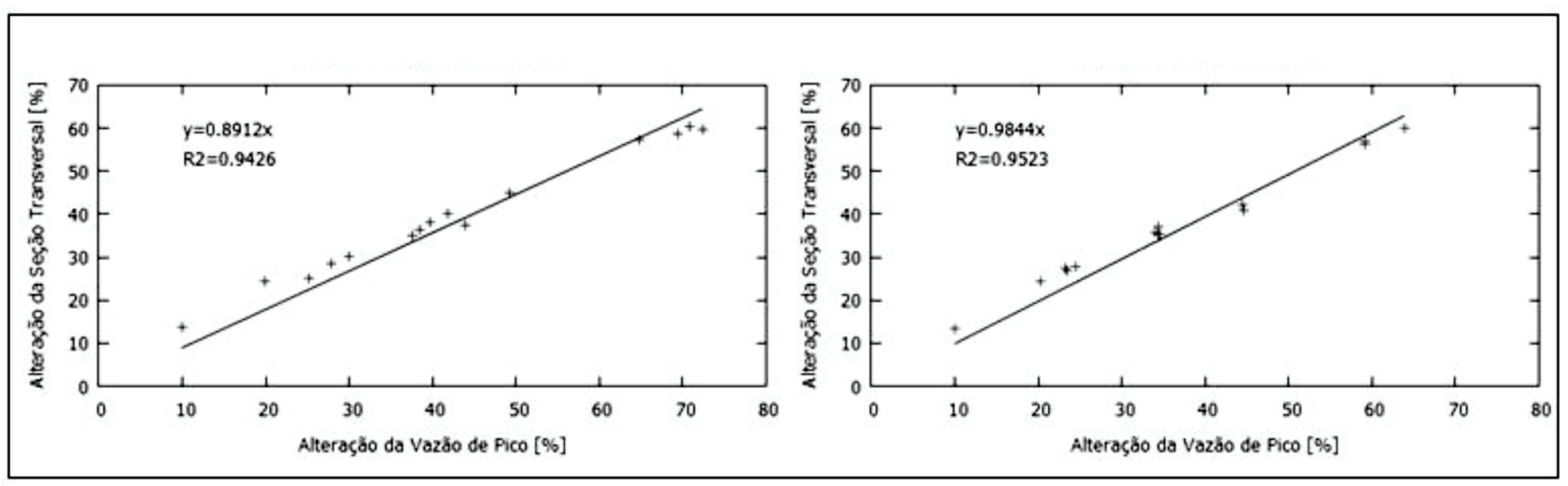

Figura 14 - Comparação do efeito da discretização espacial da bacia na vazão de pico e área da seção transversal do canal, durações $90 \mathrm{~min}$ e $24 \mathrm{hs}$
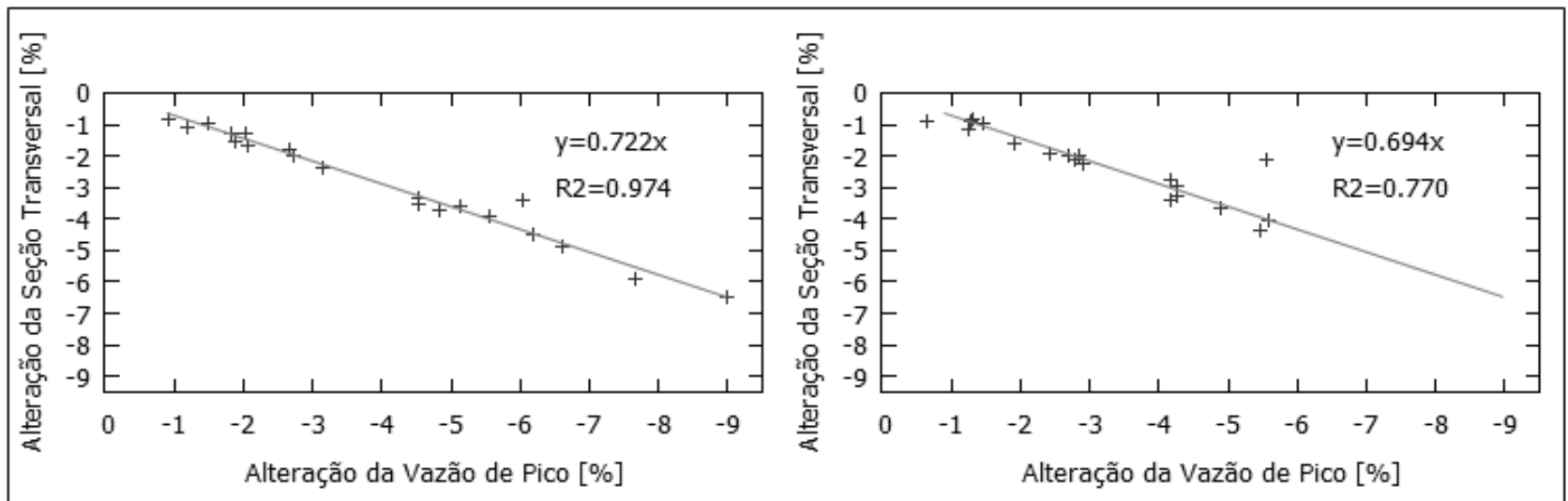

Figura 15 - Comparação do efeito do intervalo de tempo da chuva na vazão de pico e área da seção transversal do canal, durações $90 \mathrm{~min}$ e $24 \mathrm{hs}$

\section{Comparação de alterações da vazão de pico e área da seção transversal do canal}

Para permitir a comparação dos efeitos dos critérios de projeto na vazão de pico e na área da seção transversal do canal C29, foram plotadas as alterações percentuais de ambas as variáveis e ajustadas regressões lineares, em função dos resultados obtidos com o evento de duração de 90 minutos e 24 horas.

A Figura 14 apresenta a comparação do efeito da discretização espacial da bacia, e a Figura 15 apresenta a comparação do efeito do intervalo de tempo.

Observa-se na Figura 14 um comportamento quase linear entre a alteração da área da seção transversal e da vazão de pico com o aumento da discretização espacial da bacia. Entretanto, o padrão geral das retas ajustadas indica que os valores das alterações percentuais da vazão de pico são superiores aos valores das alterações percentuais da área da seção transversal, sendo que um aumento máximo de $72 \%$ na vazão de pico provocou um aumento máximo de 60\% na área da seção transversal. Por outro lado, o coeficiente angular da reta ajustada é inferior durante o evento com duração de 90 minutos, o que significa que um mesmo valor da alteração percentual na vazão de pico causará mais alteração da área da seção transversal durante o evento com duração de 24 horas.

Os resultados do efeito do intervalo de tempo na vazão de pico do hidrograma de projeto e área da seção transversal do canal C29 estão ilustrados na Figura 15. Regressões lineares foram ajustadas para representar o padrão da alteração da vazão de pico e da área da seção transversal do canal, com o aumento do intervalo de tempo. Os ajustes indicam uma tendência decrescente na vazão de pico e, em consequência, na área da seção transversal do canal com o aumento do intervalo de tempo. Comparando a Figura 15 e a Figura 14 é possível perceber que o efeito do intervalo de tempo é menos intenso em relação ao efeito da discretização espacial da bacia.

\section{CONCLUSÕES}

Neste estudo foram investigados os efeitos da discretização espacial da bacia, da posição do pico da chuva e discretização temporal do hietograma de projeto, nas principais características do hidrograma de projeto. Os mesmos efeitos foram ainda avaliados no dimensionamento hidráulico do sistema de macrodrenagem de águas pluviais dos bairros suburbanos de Mavalane "A" e Maxaquene "A", em Maputo, Moçambique. A bacia foi discretizada em 1, 5, 7 e 12 sub-bacias, e em cada sub -bacia foram calculados hidrogramas, derivados de hietogramas com discretização temporal de 1, 2, 3, 4 e 5 minutos, e com o pico localizado no início, 25\%, 50\%, 75\% e final das durações de 90 minutos e 24 horas. Os hidrogramas foram propagados no sistema de drenagem da bacia, sendo obtido o hidrograma de 
projeto resultante, através do qual foi feito o dimensionamento hidráulico de todo o sistema.

Os resultados mostraram uma influência importante dos efeitos da discretização espacial da bacia, posição do pico da chuva e intervalo de tempo, na vazão de pico, tempo de pico e volume parcial do hidrograma de projeto, bem como na área da seção transversal dos canais. O efeito da discretização espacial da bacia foi o mais intenso, chegando a causar aumentos de até $180 \%, 72 \%$ e $60 \%$ no volume parcial, vazão do pico e área da seção transversal, respectivamente. O mesmo efeito causou diminuição máxima de 53\% no tempo de pico.

O efeito da posição do pico da chuva foi o segundo mais influente, chegando a causar diminuição de $48 \%$ na vazão de pico e, consequentemente, $39 \%$ na área da seção transversal do canal para o evento com pico no início, e aumento de $10 \%$ e 7\% nas mesmas variáveis para o evento com pico aos $75 \%$. Este efeito pode causar até $100 \%$ de diminuição no volume parcial, embora dependa do valor adotado na vazão de corte do hidrograma de projeto.

O efeito do intervalo de tempo foi o menos influente, causando diminuição máxima de $28 \%, 9 \%$ e $6 \%$ no volume parcial, vazão de pico e área da seção transversal.

O efeito da discretização espacial da bacia foi o mais intenso de todos, revelando a importância que este pode ter na definição do hidrograma de projeto e, consequentemente, nas obras propostas. Deste modo é recomendável sempre que possível discretizar a bacia com vista a representar numa escala adequada a heterogeneidade dos processos hidrológicos. O efeito do intervalo de tempo no hidrograma de projeto é causado pela perda da representatividade, principalmente no seu pico. $\mathrm{Na}$ vazão de pico, área da seção transversal do canal e volume parcial do hidrograma de projeto, o efeito do intervalo de tempo é menos intenso que os efeitos da discretização espacial da bacia e posição do pico do hietograma de projeto. Contudo, mesmo observando-se que este efeito é menos intenso nos eventos de precipitação com durações maiores, é recomendável usar os menores intervalos de tempo com vista a representar melhor os hidrogramas de projeto.

\section{AGRADECIMENTOS}

O primeiro autor agradece ao CNPq pela bolsa de mestrado concedida. Os autores agradecem as contribuições dos revisores anônimos.

\section{REFERÊNCIAS}

ADAMS, B.J.; HOWARD C.D.D. Design storm pathology. Revue Canadienne des Ressources Hvdriques, v. 11, n. 3, p. 49-55, 1986.

ALLASIA, D.G. Impacto das incertezas no custo de uma rede de macrodrenagem. 2002. 146f. Dissertação (Mestrado) - Instituto de Pesquisas Hidráulicas da Universidade Federal do Rio Grande do Sul, 2002.
ALLASIA, D.G.; VILLANUEVA, O.A. Custo da incerteza na macrodrenagem urbana I: determinação dos parâmetros mais sensíveis na modelagem de macrodrenagem urbana. Revista Brasileira de Recursos Hídricos, v. 12, n. 1, p. 65-77, $2007 \mathrm{a}$.

ALLASIA, D.G.; VILLANUEVA, O.A. Custo da incerteza na macrodrenagem urbana II: influência do erro na estimativa do cn sobre o custo de investimento da rede. Revista Brasileira de Recursos Hidricos, v. 12, n. 1, p. 79-90, 2007b.

BERNI, N; VITERBO, A.; PANDOLFO C.; STELLUTI M.; BARBETTA, S.; BROCCA L. Effects of rainfall and soil/land use spatial distribution on hydrological response at different scales. Proceeding of IV iEMSs iEMSs, 470-477, 2008.

BOLETIM DA REPÚBLICA. Regulamento dos sistemas públicos de distribuição de água e drenagem de águas residuais. I série número 26. República de Moçambique, 2003. 55p.

DANIIL, E.I.; MICHAS, S.N.; LAZARIDIS, L.S. Hydrologic Modelling for the determination of design discharges in ungauged basins. Global NEST Journal, v.7, n. 3, p. 296-305, 2005.

DANKENBRING, S.C.; MAYS, D.C. Catchment discretization in the Colorado urban hydrograph procedure: a case study in the East Toll Gate creek watershed, Arapahoe county, Colorado. Urban drainage and flood control district report, 2009. 11p.

DIREÇÃO NACIONAL DE ÁGUAS. Drenagem das bacias "b" e "c" da cidade de Maputo. 2afase. Maputo, 2005. 6p.

EL-JABI, N.; SARRAF, S. Effect of maximum rainfall position on rainfall-runoff relationship. J. Hydraul. Eng, v. 117, n. 5, p. 681-685, 1991.

GHOSH, I.; HELLWEGER, F. L. Effects of spatial resolution in urban hydrologic simulations. J. Hydrol. Eng, v. 170, p. 129137, 2012.

KHAKBAZ, B.; IMAM B.; HSU K.; SOROOSHIAN S. From lumped to distributed via semi-distributed: calibration strategies for semi-distributed hydrologic models. J. Hydrology, v. 418-419, p. $61-77,2009$.

KLING, H.; GUPTA H. On the development of regionalization relationships for lumped watershed models: the impact of ignoring sub-basin scale variability. J. Hydrology, v. 373, n. 3-4, p. 337-351, 2009.

MAHUNGUANA, M. J.et al. Efeito da discretização espaçotemporal na estimativa do hidrograma de projeto. SIMPÓSIO BRASILEIRO DE RECURSOS HÍDRICOS, XX., 2013. Anais.... ABRH. Bento Gonçalves-RS. PAP012810, 2013.

MCCUEN, R. H., WONG, S. L., RAWLS, W. J. 1984, Estimating urban time of concentration. Journal of Hydraulic Engineering, $\mathrm{v}$. 110, n. 7, p. 887-904, 1984. 
QUADER, A.; GUO, Y. Peak discharge estimation using analytical probabilistic and design storm approaches. J. Hydrol. Eng, v. 11, p. 46-54, 2006.

SILVEIRA,A. L. L. Desempenho de fórmulas de tempo de concentração em bacias urbanas e rurais. Revista Brasileira de Recursos Hídricos, v. 10, n. 1, p. 5-23, 2005.

SILVEIRA, G.M. 2010. Análise de sensibilidade de hidrogramas de projeto aos parâmetros de sua definição indireta. 2010. 243 f. Dissertação (Mestrado) - Escola Politécnica da Universidade de São Paulo, 2010.

SMITHERS, J.; SCHULZE R.; KIENZLE S. Design flood estimation using a modelling approach: a case study using the ACRU model. IAHS, v. 240, p. 365-375, 1997.

ŠRAJ, M.; DIRNBEK, L.; BRILLY, M. The influence of effective rainfall on modeled runoff hydrograph. J. Hydrol. Hydromech, v. 58, n. 1, p. 3-14, 2010.

TUCCI, C. E. M. Modelos hidrológicos. Cap.9. Porto Alegre: Editora da UFRGS/ABRH, 2005. p. 415-418.

WILSON, C.B.; VALDES, J.B.; RODRIQUEZ-ITURBE, I. On the influence of the spatial distribution of rainfall on storm runoff. Water Resources Research, v. 15, n. 2, p. 321-328, 1979.

WOOD, E. F.; SIVAPALAN M.; BEVEN K.; BAND L. Effects of spatial variability and scale with implication to hydrologic modelling. J. Hydrology, v. 102, p. 29-47, 1988.

YU, Z.; LU, Q.; ZHU J.; YANG C.; JUN Q.; YANG T.; CHEN X.; SUDICKY E.A. Spatial and temporal scale effect in simulating hydrologic processes in a watershed. J. Hydrol. Eng, v. 19, n. 1, p. 99-107, 2012.

YUE, S.; OUARDA T.B.M.J.; BOBÉE B.; LEGENDRE P.; BRUNEAU P. Approach for describing statistical properties of flood hydrograph. J. Hydrol. Eng, v. 7, p. 147-153, 2002. 